\title{
COMUNICAÇÃO GOVERNAMENTAL - A MAGNA CARTA DO DUBAI
}

\author{
Diamantino Ribeiro ${ }^{1}$, António Pedro Costa ${ }^{2}$ e Jorge Remondes ${ }^{3}$ \\ ${ }^{1}$ CEFAGE - Universidade de Évora, Portugal; diamantinojtribeiro@gmail.com; \\ 2Universidade de Aveiro, Portugal; pcosta@ludomedia.pt \\ ${ }^{3}$ ISVOUGA, CETRAD - Centro de Estudos Transdisciplinares para o Desenvolvimento Portugal; jorge@jorgeremondes.eu
}

Resumo. No ano de 2019 o Governo do Dubai formalizou a sua "Magna Carta", documento que, na ausência de uma Constituição escrita, sistematiza os oito princípios que regem a governação do Emirado. O objetivo da "Magna Carta" é assegurar o bem-estar dos cidadãos, o desenvolvimento sustentável da Nação e a prosperidade das gerações futuras. Enquadrado num estudo que se vem realizando desde 2016 sobre a comunicação governamental do Dubai e EAU e em particular do Ministério da Felicidade, este trabalho tem por objetivo compreender se existe articulação entre a abordagem da Felicidade, Positividade e Bem-estar integrado no Plano Nacional de Felicidade e Positividade com a referida "Magna Carta", bem como a visibilidade dada ao tema nos media. Para a realização do estudo, consultou-se o documento e recolherem-se no corpus latente os títulos das notícias publicadas no corpus latente em língua inglesa. Através de uma abordagem qualitativa procedeu-se à análise de conteúdo do documento com o apoio do software webQDA. Os resultados permitiram inferir que, por um lado, se trata de um documento que visa manter um legado centenário e, por outro, transmitir esse legado às gerações futuras. Do ponto de vista da comunicação governamental, o documento foi amplamente divulgado e a comunicação coloca o foco na comunidade e na preocupação do governo, em trabalhar para o bem-estar da sociedade em linha com o Plano Nacional para a Felicidade lançado em 2016.

Palavras-chave: Análise de Conteúdo; Comunicação Governamental; Magna Carta; Ministério da Felicidade; Oito Princípios do Dubai.

\section{GOVERNMENT COMMUNICATION - DUBAI'S MAGNA CARTA}

Abstract. In 2019, the Government of Dubai formalized its "Magna Carta". Document that, in the absence of a written Constitution, systematizes the eight principles that guide the Emirate's governance. The purpose of the "Magna Carta" is to ensure the well-being of citizens, the sustainable development of the Nation and the prosperity of future generations. As part of a study that has been carried out since 2016 on government communication of Dubai and the UAE Government and in particular by the Ministry of Happiness, this work aims to understand whether there is an articulation between the Happiness, Positivity and Wellbeing approach integrated in the National Happiness and Positivity Program with the aforementioned "Magna Carta", as well as the visibility given to the theme in the media. To carry out the study, the document was screened and the titles of the news published in the corpus latente in English were collected. Through a qualitative approach, the content analysis of the document was carried out with the support of the webQDA software. The results allowed us to infer that, on the one hand, it is a document that aims to maintain a centenary legacy and, on the other hand, to transmit this legacy to future generations. From the point of view of government communication, the document was widely disseminated and the communication puts the focus on the community and the government's concern to working for the well-being of society in line with the National Plan for Happiness launched in 2016.

Keywords: Content Analysis; Government Communication; Magna Carta; Ministry of Happiness; 8 Principles of Dubai 


\section{INTRODUÇÃO}

O Dubai assume uma grande visibilidade local e global enquanto líder e marca no contexto da Federação dos 7 Emirados Árabes Unidos (EAU). O governo deste Emirado investe continuamente em projetos pioneiros a vários níveis e, particularmente desde 2016, vem colocando um grande enfoque na felicidade e bem-estar dos cidadãos e dos residentes no País; paralelamente o governo tem vindo a criar e implementar políticas orientadas para a sustentabilidade das gerações futuras nas quais engloba os seus valores fundamentais. $\mathrm{Na}$ ausência de uma Constituição escrita, o governo tem seguido vários princípios básicos que têm funcionado como âncora da governação após a formação da Federação nos anos 70 do século $X X$.

No ano 2019, o líder do Dubai, Sheik Mohammed bin Rashid Al Maktoum elaborou uma "Magna Carta", documento que, no seu entender, reúne os 8 princípios fundamentais da Nação. O documento assume relevância académica no âmbito do estudo alargado sobre a comunicação governamental baseado no estudo de caso do Ministério da Felicidade do Dubai e dos Emirados Árabes Unidos, criado pelo governo em fevereiro de 2016, que os autores têm vindo a desenvolver desde essa data (Ribeiro et al.,2017, 2018, 2019a, 2019b, 2019c, 2019d, 2020).

Este trabalho tem por objetivo compreender se existe articulação entre a abordagem da Felicidade, Positividade e Bem-estar integrado no Plano Nacional de Felicidade e Positividade com a referida "Magna Carta", bem como a visibilidade dada ao tema nos media.

Através de uma abordagem qualitativa recorrendo à técnica de análise de conteúdo, utilizando o software de investigação qualitativa webQDA (Costa, 2016; Costa, de Sousa, Moreira, \& de Souza, 2017; Costa, de Souza, Moreira, \& de Souza, 2018; Costa, Linhares, \& Souza, 2012; Costa, Moreira, \& Souza, 2019), além do conteúdo do próprio documento obtido no website oficial do governo, recolheram-se e analisaram-se os títulos das notícias publicadas na Internet, em língua inglesa, sobre a divulgação do documento.

\section{COMUNICAÇÃO POLÍTICA}

A investigação sobre comunicação política deverá continuar a ser um campo de estudo em evolução em sintonia com vários campos do saber. De acordo com a visão de Kenski \& Jamieson (2014) 
"como campo de investigação dinâmico dedicado ao estudo de um conjunto complexo e em constante mudança de instituições e estruturas sociais, antecipamos que o estudo da comunicação política, deverá continuar como aconteceu nas décadas passadas e aprender o melhor de campos do conhecimento relacionados, continuando a desenvolver a sua própria compreensão sobre a forma pela qual os indivíduos criam intersecções entre o poder e os símbolos e usam os símbolos para conseguir, manter e contestar o poder" (p. 917).

As mesmas autoras reconhecem que um trabalho significativo tem vindo a ser gerado no âmbito da comunicação política em todo o mundo. Importa, antes de mais, encontrar uma definição de comunicação política. Canel \& Sanders (2011) sistematizam algumas definições:

- Atividade comunicativa considerada política em virtude das suas consequências, tanto atuais como potenciais, que existe no quadro do funcionamento do sistema político;

- Símbolos políticos mais evidentes na imprensa de elite;

- Comunicação com efeitos atuais ou potenciais no funcionamento de um estado político ou de uma entidade;

- Atividade comunicativa considerada política em virtude das suas consequências atuais ou potenciais na regulação da conduta humana, quando esta se encontra em situação de conflito;

- Qualquer troca de símbolos e mensagens que está condicionado pelo sistema político e que, por sua vez, o influencia;

- Símbolos criados pelos meios de comunicação para que a sociedade mantenha a consciência da existência das suas instituições políticas, ou seja, são as imagens que ajudam a que o povo recorde que se vota, que se controla o governo e que a Constituição funciona.

Estas definições contêm aspetos comuns uma vez que todas referem, por exemplo, que a comunicação política implica a troca de mensagens e de símbolos.

Todas as definições consideram também que a comunicação obtém um carácter político devido aos seus efeitos ou consequências (intencionais ou não) para o sistema político, quer no que respeita ao estabelecimento de normas para a conduta humana, para os políticos e jornalistas, quer relativamente ao exercício da política. 
A comunicação política acontece quando a comunicação afeta a atividade política, ou seja, quando a comunicação tem consequências políticas (Canel \& Sanders, 2011).

Apesar de a definição de comunicação política variar de académico para académico, à semelhança do que demonstraram Canel \& Sanders (2011), a linha comum das várias definições, no geral, centra-se na mensagem (Kenski \& Jamieson, 2014).

Por outro lado, na atualidade, num ambiente em que as ideias são transformadas em conteúdo que é rapidamente divulgado, adaptado ou modificado pelos utilizadores, as mensagens não são nem estáveis nem limitadas por começos prontamente discernidos e fins óbvios (Kenski \& Jamieson, 2014).

A disponibilidade de tecnologias capazes de adaptar informações baseadas na preferência do utilizador têm vindo, por seu turno, a redirecionar o foco da investigação para a seleção individual, com as mensagens orientadas para indivíduos identificados por atributos que eles compartilham com um subconjunto de outros (Sterling, Jost, \& Hardin, 2019).

No mesmo sentido, as constantes evoluções tecnológicas estão a conduzir a aposta da política para os novos media, nomeadamente as redes sociais. Estas permitem uma melhor comunicação com o seu público-alvo (Canavilhas, 2002; Pereira, 2012).

À semelhança do que acontece com a comunicação política, pode dizer-se que atualmente a definição de comunicação governamental é diferente de autor para autor, variando de uma associação com formas de atividade política, para um foco específico, como publicidade política (Kunsch, 2003; McKinzie, 1993; Mikler, 2016; Viteritti Joseph, 1997).

Assim, os governos atuais têm mudado cada vez mais para um modo de consulta que inclui a internacionalização e a exigência de novas práticas de comunicação em muitas jurisdições. Isso inclui o desenvolvimento e o uso de instrumentos que promovem recursos, como a liberdade de legislação da informação e o uso de medidas de desempenho público (Howlett, 2009; Kanozia, 2016; Knapp \& Wright, 2006).

Como resultado, a comunicação governamental é agora uma indústria em crescimento em muitos países e sujeito a aumentar a atenção de ambos os profissionais e teóricos (Howlett, 2009). A investigação sobre os países desenvolvidos indica que a melhoria na forma como o governo comunica com o público pode aumentar a confiança no governo e a satisfação com os serviços públicos (Nussio, García-Sánchez, Oppenheim, \& Pantoja-Barrios, 2020). 
Em síntese, conforme defendem Canel \& Sanders (2011), a comunicação política é a atividade de diversas pessoas e instituições (políticos, comunicadores, jornalistas, cidadãos), em que, como consequência da interação, se produz uma troca de mensagens com as quais se articula a tomada de decisões políticas assim como a aplicação destas na comunidade.

De salientar ainda que se entende que a comunicação efetiva da informação na forma certa, às pessoas certas e no momento certo é crucial.

Para além disso, no nosso ponto de vista, a capacidade de diálogo efetivo, colaboração e comunicação derrubam barreiras verticais e horizontais à comunicação e ampliam a autoridade de forma a incluir stakeholders (Christensen \& Lægreid, 2005).

\section{OS 8 PRINCÍPIOS DO DUBAI OU "MAGNA CARTA"}

Este documento denominado "Os 8 Princípios do Dubai", igualmente designado por "Magna Carta" do Dubai, foi dado a conhecer em 05 de janeiro de 2019'. Na apresentação do documento o Sheik Mohammed bin Rashid Al Maktoum, 'Ruler' (Líder máximo) do Dubai e Primeiro Ministro dos EAU, exortou todos os que estão em posição de responsabilidade no Emirado a respeitarem esses princípios, garantindo a sua implementação em todos os eventos e compromissos, referindo que tais princípios garantirão o bem-estar do povo, o progresso sustentado da nação e o bem-estar das gerações futuras ${ }^{2}$

O texto que acompanha os "8 Princípios", refere que estes são os princípios definidores sobre os quais o Dubai foi fundado e tem sido governado ao longo dos anos; destina-se a garantir o bem-estar do povo, o progresso sustentado da nação e o bem-estar das futuras gerações. No mesmo texto, S. Alteza faz um apelo às gerações futuras para preservarem esses princípios e entregá-los àqueles que os sucederem.

No quadro seguinte apresentam-se os 8 Princípios?:

\footnotetext{
1 Os 8 Princípios do Dubai ou Magna Carta. Disponível em: https://www.government.ae/en/about-the-uae/the-uaegovernment/the-local-governments-of-the-seven-emirates Consultado em: 14 de fevereiro de 2020.

${ }^{3}$ Nota dos autores: as palavras e frases em destaque no texto descritivo de cada Princípio foram selecionadas pelos autores.
} 
Quadro 1. Os 8 Princípios ou Magna Carta do Dubai

Princípios

1. A União é a Fundação

2. Ninguém está acima da lei

3. Somos uma capital comercial

4. Três fatores impulsionam crescimento

5. A nossa sociedade tem uma personalidad e única

6. Acreditamos na diversificaçã o económica.

7. Uma terra para talentos

8. Preocupamonos com as gerações futuras
Texto do Princípio

O Dubai é parte integrante dos Emirados Árabes Unidos e um pilar da Federação. O destino do Emirado está entrelaçado com o destino dos Emirados Árabes Unidos, o seu bem-estar é vital para os Emirados Árabes Unidos e o seu povo está sempre disposto a sacrificar-se pelo bem maior do país. O interesse da União está acima do interesse local, as leis da União transcendem as nossas leis e legislações, a política da União é a nossa política e as prioridades governamentais da União são as prioridades do nosso governo.

A justiça é a base de uma nação forte e orgulhosa e garante prosperidade e estabilidade. Ninguém está acima da lei no Dubai, começando pela família governante. A lei não discrimina cidadãos e residentes, ricos e pobres, homens e mulheres, muçulmanos e não muçulmanos. Justiça atrasada é justiça negada. "A injustiça em qualquer lugar é uma ameaça à justiça em todo lugar". Eu renuncio a práticas ou condutas injustas de qualquer pessoa, e a família governante também renuncia a qualquer forma de injustiça, desde que governa o Emirado.

O governo do Dubai tem como objetivo melhorar a vida do seu povo, fortalecendo sua economia. O Dubai não investe nem se envolve em política e não depende de política para garantir sua competitividade. Estendemos uma mão de amizade a todos aqueles que têm boas intenções em relação ao Dubai e aos Emirados Árabes Unidos. O Dubai é um centro global favorável aos negócios, politicamente neutro, que se concentra na criação de oportunidades económicas.

O crescimento do Dubai é impulsionado por três fatores: um governo credível, resiliente e excelente; um setor privado ativo, justo e aberto; e principais empresas públicas e estatais que competem globalmente e geram rendimento e ativos para o governo, empregos para os seus cidadãos e para as gerações futuras.

A nossa sociedade é respeitosa e coerente, vinculada à tolerância e à abertura. Distanciase de todas as formas de discriminação e preconceito. É uma sociedade disciplinada, comprometida com as suas promessas, acordos e convénios. Somos modestos em relação aos nossos sucessos, perseverantes em lidar com os desafios, caridosos e generosos em alcancar o bem maior e abertos a todos.

A diversificação económica é a base da Constituição não escrita do Dubai desde 1833. Os tempos de mudança e os rápidos desenvolvimentos tornam o nosso compromisso com esse princípio eterno. O nosso novo objetivo é criar pelo menos um novo setor económico a cada três anos que seja produtivo, contribua para o nosso PIB e gere empregos.

O Dubai sempre confiou em talentosos comerciantes, executivos, engenheiros, criativos e sonhadores para seu sucesso. A sustentabilidade e a competitividade do Emirado dependem da sua capacidade de continuar atraindo pessoas qualificadas e talentosas e de nutrir as mentes mais brilhantes para gerar ideias inovadoras. Temos que rever e renovar continuamente as nossas políticas e procedimentos para garantir o nosso apelo a indivíduos talentosos. Precisamos construir o melhor ambiente no Dubai para as principais mentes do mundo.

O destino das nossas futuras gerações não deve ser afetado pelas flutuações da política regional e dos ciclos económicos globais. Investimos e criamos ativos valiosos para eles. A nossa regra fundamental a esse respeito é que o governo deve, em todas as circunstâncias, possuir ativos económicos que valham pelo menos 20 vezes o valor de seu orçamento anual. Trabalhamos para manter um futuro seguro e hoje estamos focados em garantir a prosperidade das nossas futuras gerações. 


\section{O PLANO NACIONAL DA FELICIDADE E POSITIVIDADE}

Para se perceber e se estabelecer uma relação da "Magna Carta" com o Plano Nacional da Felicidade e Positividade (PNFP) do Dubai e dos EAU apresentado pela Ministra de Estado da Felicidade Ohood Al Roumi e aprovado pelo Sheik Mohammed Al Maktoum no dia 20 de março de $2016^{4}$, data em que se assinala do Dia Internacional da Felicidade, criado pela Organização das Nações Unidas (ONU) ${ }^{5}$.

O PNFP define políticas, programas e serviços governamentais que permitem promover as vantagens de um estilo de vida positivo na comunidade e um plano para o desenvolvimento de um índice de felicidade para medir a satisfação das pessoas ${ }^{6}$. O PNFP compreende 3 áreas principais ${ }^{7}$ :

1. Inclusão da felicidade nas políticas, programas e serviços de todos os órgãos governamentais bem como no ambiente de trabalho;

2. Consolidação dos valores de positividade e felicidade como um estilo de vida na comunidade dos Emirados Árabes Unidos;

3. Desenvolvimento de ferramentas e índices para medir os níveis de felicidade.

O PNFP destina-se aos emiratis, residentes, visitantes e expatriados; procura incentivar os setores governamental e privado a lançar, recomendar e adotar iniciativas nesse sentido ${ }^{8}$. $O$ plano inclui ainda iniciativas para a publicação de conteúdos científicos e culturais, livros sobre felicidade e incentivo à leitura sobre a importância da positividade e felicidade como forma de um estilo de vida integrado. O programa apresentado pelo Governo e aprovado na data atrás mencionada também previa: a) a nomeação de um CEO para a felicidade e positividade em todos os órgãos governamentais; b) o estabelecimento de conselhos de felicidade e positividade em entidades federais; c) a alocação de horas para programas e

${ }^{4}$ National Happiness Program and National Happiness Charter. Disponível em: ernment.ae/en/about-the-uae/theuae-government/government-of-future/happiness. Consultado em 20 de fevereiro de 2020.

5 International Day of Happiness. 20 March. Disponível em: https://www.un.org/en/observances/happiness-day. Consultado em 20 de fevereiro de 2020.

${ }^{6}$ Mohammed reviews UAE Programme for Happiness and Positivity. Disponível em: https://www.emirates247.com/news/government/mohammed-reviews-uae-programme-for-happiness-andpositivity-2016-03-07-1.623503. Consultado em 20 de fevereiro de 2020.

${ }^{7}$ National Happiness Program and National Happiness Charter. Disponível em: ernment.ae/en/about-the-uae/theuae-government/government-of-future/happiness. Consultado em 20 de fevereiro de 2020.

${ }^{8}$ Idem.

9 Idem. 
atividades relacionadas com a felicidade, no governo federal; d) a criação de escritórios da felicidade e positividade; e) centros de atendimento ao cliente transformados em centros de felicidade do cliente; f) programas especiais adaptados para mudar a cultura dos funcionários do governo, para servir os clientes e torná-los felizes; g) o programa também inclui índices anuais, pesquisas e relatórios para medir a felicidade, em todos os segmentos da comunidade ${ }^{10}$.

Em síntese, como demonstra a figura 1, o programa coloca, o foco na Felicidade e Positividade de toda a comunidade, apelando para a mudança do estilo de vida liderado pelas iniciativas e políticas governamentais (Costa \& Ribeiro, 2019; Ribeiro et al., 2017, 2018, 2019a, 2019b, 2019c, 2019d,2020).

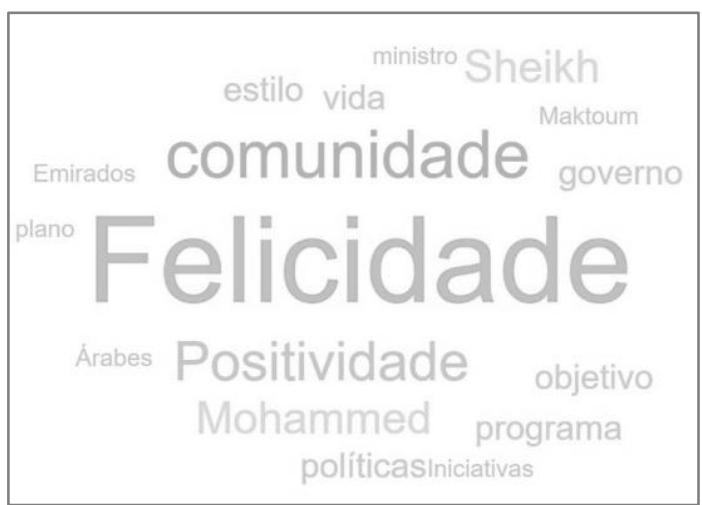

Figura 1. Palavras em destaque no Programa Nacional da Felicidade e Positividade (Ribeiro et al., 2017)

A Felicidade e Positividade está bem patente na agenda interna do próprio Governo, sendo que o Ministério da Felicidade tem por missão criar e implementar iniciativas e políticas governamentais destinadas a promover um novo estilo de vida junto de toda a comunidade, incluindo a sua difusão ao nível internacional.

\section{METODOLOGIA}

A metodologia qualitativa, muito utilizada nas ciências sociais, é reconhecida como sendo um campo de investigação, com direito próprio, que é transversal a várias disciplinas. Conforme defende Bardin (2009), a metodologia qualitativa é vista como um meio para explorar e para entender o significado que os indivíduos ou os grupos atribuem a um problema social e humano. Dentro da metodologia qualitativa, recorreu-se à técnica de análise de conteúdo. A técnica da análise de conteúdo caracteriza-se pela procura de

\footnotetext{
${ }^{10}$ Ibidem.
} 
explicação e compreensão, permitindo fazer inferências que, de forma sistemática e objetiva, identificam características singulares e implícitas do discurso, já que procura conhecer aquilo que está por trás das palavras sobre as quais se debruça em busca de outras realidades (Bardin, 2009). A análise de conteúdo permite desenvolver conceitos e ideias a partir de padrões encontrados nos dados. Este tipo de método foca-se no entendimento dos problemas, analisando os valores, os comportamentos e as atitudes, não colocando problemas de validade e fiabilidade dos instrumentos e não se preocupando com a generalização dos resultados e com as dimensões das amostras (Krippendorff, 1990). Na atualidade, a análise de conteúdo consiste num conjunto de instrumentos metodológicos que objetiva a análise de diferentes fontes de conteúdos tanto verbais como não-verbais. Relativamente à sua realização prática, esta abrange várias etapas, nomeadamente para que se possa confirmar toda a significação dos dados recolhidos. De acordo com Bardin (2009), estas etapas encontram-se, por sua vez, organizadas em três fases distintas: 1) préanálise; 2) exploração do material; e 3) tratamento dos resultados, inferência e interpretação. Para Krippendorff (1990), a análise de conteúdo é uma técnica de investigação que permite fazer inferências, válidas e replicáveis, dos dados para o seu contexto. Por isso, as inferências fazem-se sobre o que é que pode incidir no tipo de interpretação de análise, numa base de estabelecimento de uma relação entre os dados obtidos (Amado, Costa, \& Crusoé, 2017).

Importa referir a origem dos dados. Conforme mencionado, os dados foram recolhidos na internet ou corpus latente. Bauer \& Gaskell (2010) definem o corpus de um tema como o conjunto de matérias identificadas como fontes importantes para que o investigador seja capaz de fundamentar o seu texto, sempre adequado ao carácter científico do seu trabalho, seja ele relatório, dissertação, tese, ou outro tipo de trabalho. O corpus de uma pesquisa refere-se à recolha de dados, que são as evidências da realidade, que permitirão avaliar os fatos reais a partir das amostras recolhidas (Pina, Neri de Souza, \& Leão, 2013). Por seu turno o corpus latente diz respeito à existência de grandes bases de dados com as quais toda a gente pode trabalhar, nomeadamente a Internet, que dia após dia vai acumulando cada vez mais e mais informação em forma de textos, imagens e vídeos, entre outros (Pina et al., 2013). O corpus latente é, então, um conjunto de conteúdos disponíveis, na internet, para quem deseje e tenha as competências e qualificações necessárias para os extrair (Pina et al., 2013). Essa extração deverá ser suportada por uma estruturação ou codificação. 
No que diz respeito à codificação, Bardin (2009), avança com uma definição, atribuindo-Ihe o significado de transformação, mais concretamente através do recorte, agregação e enumeração, e com base em determinadas regras precisas sobre todas as informações textuais, que acabam por representar todas as características do conteúdo.

A codificação assume particular relevância no apoio à criação de referências para análise de conteúdo com apoio do software webQDA. A utilização destas ferramentas tecnológicas designadas por Computer Assisted Qualitative Data Analysis Software têm vindo a tornar-se instrumentos de grande apoio à investigação suportada na metodologia qualitativa a partir de diversas fontes de recolha de dados, através das quais é possível recolher grandes volumes de dados, conforme referem Baugh, Hallcom, \& Harris (2010):

\footnotetext{
"a análise qualitativa e os CAQDAS tornaram-se ferramentas valiosas no arsenal da investigação. Os estudos qualitativos são mais prevalentes no ambiente académico atual, onde é observada a adesão a práticas metodológicas robustas (...) O CAQDAS pode apoiar um melhor entendimento de variáveis complexas e subjetivas extraídas de questionários abertos, entrevistas, pesquisas na Internet e outros meios de recolha de dados qualitativos (Baugh, Hallcom, Harris, 2010, p. 79).
}

A opção pelo webQDA pretende-se, entre outros aspetos, com o fato de ser considerado uma ferramenta que impele os investigadores a adotar uma abordagem mais inquisitiva aos dados com os quais lidam nos seus estudos qualitativos (Costa et al., 2018).

Para a realização da análise qualitativa procedeu-se em primeiro lugar à recolha dos dados no corpus latente. Realizaram-se várias leituras dos artigos da "Magna Carta" em língua inglesa; ação que se repetiu após a tradução para português. De seguida, efetuou-se uma breve comparação com os principais conceitos do Programa Nacional da Felicidade e Positividade, uma vez que este é um dos programas-âncora do estudo que vem sendo realizado pelos autores desde 2016, no âmbito da comunicação governamental do Ministério da Felicidade do Dubai e dos Emirados Árabes Unidos. Depois procedeu-se à inserção dos artigos da Magna Carta e à criação dos códigos no webQDA. Por fim, realizou-se uma recolha, igualmente no corpus latente, dos títulos das notícias publicadas sobre os "8 Princípios do Dubai" de forma a compreender a divulgação e a visibilidade criada pelo governo em torno do assunto.

\section{APRESENTAÇÃO E DISCUSSÃO DOS RESULTADOS}

Com base no texto dos 8 Princípios, criaram-se códigos de referência no software de análise. A partir dos dados obtidos foi possível elaborar um quadro que coloca em destaque as palavras ou temas-chave de cada um dos Princípios da Magna Carta (Quadro 2): 
Quadro 2. Palavras e conceitos-chave selecionados

\begin{tabular}{|c|c|}
\hline PRINCIPIO & Palavras/Temas chave \\
\hline $\begin{array}{l}\text { 1. A União é a Fundação do } \\
\text { Dubai }\end{array}$ & bem-estar \\
\hline 2. Ninguém está acima da lei & prosperidade e estabilidade \\
\hline $\begin{array}{l}\text { 3. Somos uma capital } \\
\text { comercial }\end{array}$ & $\begin{array}{l}\text { melhorar a vida do seu povo | centro global que se concentra na } \\
\text { criação de oportunidades económicas. }\end{array}$ \\
\hline $\begin{array}{l}\text { 4. Três fatores impulsionam } \\
\text { o crescimento }\end{array}$ & $\begin{array}{l}\text { 1. um governo credível, resiliente e excelente; } \\
\text { 2. um setor privado ativo, justo e aberto; } \\
\text { 3. principais empresas públicas e estatais que competem } \\
\text { globalmente e geram rendimento e ativos para o governo, } \\
\text { empregos para os seus cidadãos e para as gerações } \\
\text { futuras }\end{array}$ \\
\hline $\begin{array}{l}\text { 5. A nossa sociedade tem } \\
\text { uma personalidade única }\end{array}$ & $\begin{array}{l}\text { sociedade disciplinada, comprometida com as suas promessas I } \\
\text { caridosos e generosos em alcançar o bem maior e abertos a } \\
\text { todos }\end{array}$ \\
\hline $\begin{array}{l}\text { 6. Acreditamos na } \\
\text { diversificação económica }\end{array}$ & $\begin{array}{l}\text { base da Constituição não escrita do Dubai desde } 1833 \text { | } \\
\text { compromisso com esse princípio eterno }\end{array}$ \\
\hline 7. Uma terra para talentos & $\begin{array}{l}\text { sustentabilidade | competitividade | gerar ideias inovadoras | atrair } \\
\text { pessoas qualificadas e talentosas }\end{array}$ \\
\hline $\begin{array}{l}\text { 8. Preocupamo-nos com as } \\
\text { gerações futuras }\end{array}$ & $\begin{array}{l}\text { Investimos e criamos ativos valiosos para eles | um futuro seguro } \\
\text { e hoje estamos focados em garantir a prosperidade das nossas } \\
\text { futuras gerações }\end{array}$ \\
\hline
\end{tabular}

Fonte: Magna Carta - resultados obtidos com o apoio do software webQDA

Do quadro pode inferir-se, em primeiro lugar, que apesar de vários dos princípios estarem relacionados com a economia ou desenvolvimento económico do Emirado, o bem-estar, a sustentabilidade e o sentido de comunidade, assim como o posicionamento do Emirado no mundo, assumem um lugar de destaque no conteúdo da "Magna Carta". Em segundo lugar, entende-se que está bem patente a preocupação de criar um compromisso no presente e para o futuro relativamente aos valores defendidos pelos fundadores e continuadores da governação.

Comparativamente com o Programa Nacional da Felicidade e Positividade, descrito de forma sucinta no capítulo 4, pode inferir-se que a "Magna Carta" tem um maior enfoque nas qualidades do País, no seu potencial económico, na sua capacidade de inovar e de atrair talento, por exemplo. No entanto, fica bem claro logo no primeiro princípio que o objetivo do governo é trabalhar para o bem-estar de todos os cidadãos. Esse é também um dos grandes objetivos do PNFP, que além de promover a felicidade e a positividade pretende alcançar o bem-estar dos cidadãos. 
No que diz respeito à divulgação do documento designado por "Magna Carta", recolheramse os títulos das notícias publicadas por vários órgãos de media locais em língua inglesa; a recolha realizou-se exclusivamente no corpus latente e exclui as redes sociais, conforme se apresenta no Quadro 3:

Quadro 3. Divulgação da Magna Carta nos media locais (em língua inglesa)

\begin{tabular}{|c|c|c|}
\hline Título & Publicação & Link \\
\hline $\begin{array}{l}\text { Sheikh Mohammed unveils the } 8 \\
\text { principles of Dubai }\end{array}$ & Kaleej Times & $\begin{array}{l}\text { https://www.khaleeitimes.com/nation/sheikh- } \\
\text { mohammed-unveils-the-8-principles-of-dubai- }\end{array}$ \\
\hline $\begin{array}{l}\text { Sheikh Mohammed issues eight } \\
\text { principles of governance to strengthen } \\
\text { growth and tolerance }\end{array}$ & The National & $\begin{array}{l}\text { https://www.thenational.ae/uae/sheikh-mohammed- } \\
\text { issues-eight-principles-of-governance-to- } \\
\text { strengthen-growth-and-tolerance-1.809562 }\end{array}$ \\
\hline $\begin{array}{l}\text { Sheikh Mohammed unveils eight } \\
\text { principles of Dubai }\end{array}$ & The Gulf Time & $\begin{array}{l}\text { https://emirates-business.ae/sheikh-mohammed- } \\
\text { unveils-eight-principles-of-dubai/ }\end{array}$ \\
\hline $\begin{array}{l}8 \text { Principles of Governance in Dubai } \\
\text { issued by Sheikh Mohammad }\end{array}$ & Yes Gulf & $\begin{array}{l}\text { http://yesgulf.com/8-principles-of-governance-in- } \\
\text { dubai-issued-by-sheikh-mohammad/ }\end{array}$ \\
\hline $\begin{array}{l}\text { UAE Press: Eight principles to live } \\
\text { and thrive }\end{array}$ & WAM - & http://wam.ae/en/details/1395302730874 \\
\hline $\begin{array}{l}\text { JUST IN: HH Sheikh Mohammed Has } \\
\text { Unveiled EIGHT Principles of Dubai } \\
\text { And Urged Everyone to Abide by } \\
\text { Them }\end{array}$ & Lovin Dubai & $\begin{array}{l}\text { https://lovindubai.com/dubai/eight-principles-of- } \\
\text { dubai-hh-sheikh-mohammed }\end{array}$ \\
\hline $\begin{array}{l}\text { DEWA first public body to align vision } \\
\text { to the } 8 \text { principles of governance of } \\
\text { HH Sheikh Mohammed bin Rashid Al } \\
\text { Maktoum }\end{array}$ & DEWA & $\begin{array}{l}\text { https://electricenergyonline.com/article/energy/cate } \\
\text { gory/general/90/744077/dewa-first-public-body-to- } \\
\text { align-vision-to-the-8-principles-of-governance-of- } \\
\text { hh-sheikh-mohammed-bin-rashid-al-maktoum.html }\end{array}$ \\
\hline $\begin{array}{l}\text { Dubai Customs ties strategy to the } 8 \\
\text { principles of governance }\end{array}$ & Dubai PR Network & http://m.dubaiprnetwork.com/pr.asp?pr=136689 \\
\hline $\begin{array}{l}\text { Secrets of Success }-8 \text { Principles of } \\
\text { Sheikh Mohammed Bin Rashid Al } \\
\text { Maktoum's Governance }\end{array}$ & $\begin{array}{ll}\text { Alliance } & \text { Business } \\
\text { Advisors } & \end{array}$ & $\begin{array}{l}\text { https://alliance-dubai.net/our-services/dubai- } \\
\text { business-news-newsletter/newsletter-july- } \\
\text { 2019/secrets-of-success-8-principles-of-sheikh- } \\
\text { mohammed-bin-rashid-al-maktoum-s-governance }\end{array}$ \\
\hline $\begin{array}{l}\text { Mohammed bin Rashid to guide and } \\
\text { implement the } 8 \text { principles }\end{array}$ & Teller Report & $\begin{array}{l}\text { https://www.tellerreport.com/news/--mohammed- } \\
\text { bin-rashid-to-guide-and-implement-the-8-principles- } \\
\text { H1gR3jsA-4.html }\end{array}$ \\
\hline $\begin{array}{l}\text { His Highness Sheikh Mohammed bin } \\
\text { Rashid Al Maktoum Celebrates } 50 \\
\text { Years of Governance } \\
\text { And shares his 8-principle rule to a } \\
\text { nation's success }\end{array}$ & Expat Woman & $\begin{array}{l}\text { https://www.expatwoman.com/dubai/guide/explore- } \\
\text { dubai/his-highness-sheikh-mohammed-bin-rashid- } \\
\text { al-maktoum-celebrates-50-years-of }\end{array}$ \\
\hline $\begin{array}{l}\text { Sheikh Mohammed unveils the } 8 \\
\text { principles of Dubai }\end{array}$ & UAE Business Zone & $\begin{array}{l}\text { https://uaebusinesszone.com/2019/01/05/sheikh- } \\
\text { mohammed-unveils-the-8-principles-of-dubai/ }\end{array}$ \\
\hline $\begin{array}{l}\text { The eight principles of Dubai } \\
\text { governance }\end{array}$ & UAE Government & $\begin{array}{l}\text { https://www.government.ae/en/about-the-uae/the- } \\
\text { uae-government/the-local-governments-of-the- } \\
\text { seven-emirates }\end{array}$ \\
\hline
\end{tabular}

O quadro permite verificar que existiu uma divulgação significativa do documento, não apenas nos media mais especializados em política e/ou economia (Cf. coluna 'publicação' 
do quadro 3). Observa-se ainda, a partir dos títulos, que algumas empresas do setor público (como a DEWA) e privadas (como a Alliance Business Network) procederam de imediato ao ajustamento da missão das respetivas organizações em função deste novo documento. Esta ação vai ao encontro da visão de (Sanderson, 2001) que considera que a comunicação efetiva da informação na forma certa, às pessoas certas e no momento certo é crucial. Para além disso, entende-se que a capacidade de diálogo efetivo, colaboração e comunicação derrubam barreiras verticais e horizontais à comunicação e ampliam a autoridade de forma a incluir stakeholders; precisamente um dos pontos que o governo do Dubai foca com maior frequência, o envolvimento de toda a comunidade Princípios e todos os setores da sociedade.

No geral, entende-se que este estudo assume um contributo muito relevante para a análise da comunicação governamental do Dubai e dos EAU, sobretudo pelo foco "na mensagem", seguindo os parâmetros teóricos conforme descritos, por exemplo, por (Kenski \& Jamieson, 2014). Paralelamente, comprova a preocupação do governo em recorrer aos media para dar a conhecer as suas iniciativas, conforme também demonstrado. Também neste aspeto, 0 governo segue os cânones teóricos, as constantes evoluções tecnológicas estão a conduzir a aposta da política para os novos media. Estas permitem uma melhor comunicação com o seu público-alvo (Canavilhas, 2002; Pereira, 2012).

A Magna Carta é um documento marcante para a vida política, económica e social do País e, conforme atrás referido, o estudo permitiu verificar que existe um alinhamento narrativo com o Plano Nacional da Felicidade e Positividade.

\section{CONSIDERAÇÕES FINAIS}

Não existindo uma Constituição escrita no Dubai, o Sheik Mohammed bin Rashid Al Maktoum, por ocasião dos 50 anos da sua liderança na governação do País, celebrados no início de 2019, criou um documento que agrega os principais valores que vinham sendo transmitidos de líder para líder desde a fundação do Emirado no séc. XX. A transcrição destes valores, no contexto e à luz do século XXI, pode ser entendida como um legado para as gerações presentes e futuras dos cidadãos nativos, mas não exclusivamente.

No contexto do estudo que se vem realizando desde 2016 este trabalho permite reafirmar que, apesar de o Dubai figurar nos lugares cimeiros da inovação, tecnologia e economia, o seu governo, e em particular o seu líder máximo, preocupa-se em vincar os valores 
fundamentais da nação, transmiti-los de uma maneira formal às gerações futuras e deixar para elas instrumentos-guia, como é o caso dos "8 Princípios para o Dubai" ou da Carta dos 50 anos (50 Year Charter ${ }^{11}$ ). Neste sentido, os princípios narrados na "Magna Carta", descrevem mecanismos que permitem dar continuidade à prosperidade económica do País (como por exemplo através da criação de, pelo menos, um novo setor económico a cada três anos que seja produtivo, contribua para o PIB e gere empregos - Princípio 6), à manutenção do elo de ligação com a Federação (Princípio 1) e ao claro papel no mundo global (Princípio 3).

Por fim, de referir que tal como no Plano Nacional da Felicidade e da Positividade, concluiuse que a preocupação primordial do governo do Dubai é o de desenvolver constantemente políticas para o bem-estar dos cidadãos (Cf. Princípios 1, 3 e 8).

Do ponto de vista da comunicação governamental, como se referiu no ponto anterior, entende-se que assume particular relevância para este trabalho, a grande capacidade de criar e divulgar elementos marcantes para a história do Emirado e o apelo continuado ao envolvimento de toda a comunidade.

\section{REFERÊNCIAS}

Amado, J., Costa, A. P., \& Crusoé, N. (2017). A Técnica de Análise de Conteúdo. In Manual de Investigação Qualitativa em Educação.

Bardin, L. (2009). Análise de conteúdo (3rd ed.). Lisboa: Edições 70.

Bauer, M., \& Gaskell, G. (2010). Pesquisa qualitativa com texto, imagem e som - Um Manual Prático. Petropolis Vozes.

Baugh, Hallcom, H. (2010). Computer Assisted Qualitative Data Analysis software: a practical perspective for applied for applied research. Revista Del Instituto Internacional de Costos, (No 6), 69-81.

Baugh, J. B., Hallcom, A. S., \& Harris, M. E. (2010). Computer assisted qualitative data analysis software: A practical perspective for applied research. Revista Digital Del Instituto Internacional de Costos, (6), 69-81. Retrieved from http://dialnet.unirioja.es/descarga/articulo/3363789.pdf

Canavilhas, J. (2002). A Comunicação Política na Era da Internet.

Canel, M. J., \& Sanders, K. (2011). Government Communication. International Encyclopedia of Communication Online.

Christensen, T., \& Lægreid, P. (2005). Trust in Government: The Relative Importance of Service Satisfaction, Political Factors, and Demography. Public Performance \& Management Review, 28(4), 487-511. https://doi.org/10.1080/15309576.2005.11051848

Correia, L., Gouveia, S., \& Martins, P. (2019). The European wine export cycle. Wine Economics and Policy, 8(1),

11 The Fifty-Year Charter. Disponível em: https://government.ae/en/about-the-uae/strategies-initiatives-and-awards/localgovernments-strategies-and-plans/the-fifty-year-charter. Consultado em 27 de fevereiro de 2020. 
91-101. https://doi.org/10.1016/j.wep.2019.04.001

Costa, A. P. (2016). Cloud Computing em Investigação Qualitativa: Investigação Colaborativa através do software webQDA. Fronteiras: Journal of Social, Technological and Environmental Science, 5(2), 153. https://doi.org/10.21664/2238-8869.2016v5i2.p153-161

Costa, A. P., de Sousa, F. N., Moreira, A., \& de Souza, D. N. (2017). Research through Design: Qualitative Analysis to Evaluate the Usability (pp. 1-12). https://doi.org/10.1007/978-3-319-43271-7_1

Costa, A. P., de Souza, F. N., Moreira, A., \& de Souza, D. N. (2018). webQDA 2.0 Versus webQDA 3.0: A Comparative Study About Usability of Qualitative Data Analysis Software (pp. 229-240). https://doi.org/10.1007/978-3-319-58965-7_16

Costa, A. P., Linhares, R., \& Souza, F. N. de. (2012). Possibilidades de Análise Qualitativa no webQDA e colaboração entre pesquisadores em educação em comunicação. Educação e Comunicação, 276-286.

Costa, A. P., Moreira, A., \& Souza, F. N. (2019). webQDA - Qualitative Data Analysis. Aveiro - Portugal: Aveiro University and MicrolO. Retrieved from www.webqda.net

Costa, A. P., \& Ribeiro, D. (2019). "Analysis of Government Communication on the Establishment of the Dubai and United Arab Emirates Ministry of Happiness". In TASK2019 - (Towards Advanced Scientific Knowledge in Business Sciences) - - 3a AFU International Conference. Dubai.

Howlett, M. (2009). Government communication as a policy tool a framework for analysis. Canadian Science Review. The Canadian Political Science Review, 3(2), 23-37.

Kanozia, R. (2016). Environment communication for sustainable development in Punjab, India. Journal of Content, Community and Communication, 4, 41-49.

Kenski, K., \& Jamieson, K. H. (Eds.). (2014). The Oxford Handbook of Political Communication (Vol. 1). Oxford University Press. https://doi.org/10.1093/oxfordhb/9780199793471.001.0001

Knapp, A., \& Wright, V. (2006). The Government and Politics of France. Routledge. Retrieved from http://elibrary.bsu.az/books_400/N_338.pdf

Krippendorff, K. (1990). Metodología de análisis de contenido : teoría y práctica. Ediciones Paidós.

Kunsch, M. (2003). Planejamento de relações públicas na comunicação integrada. São Paulo: Summus.

McKinzie, S. (1993). Public sector communication: How organizations manage information. Government Publications Review, 20(6), 721-722. https://doi.org/10.1016/0277-9390(93)90086-5

Mikler. (2016). Political contestation and the emergence of new actors, but who governs? A response to Michael Strange. Global Discourse, 6(3), 370-373. https://doi.org/10.1080/23269995.2015.1104984

Nussio, E., García-Sánchez, M., Oppenheim, B., \& Pantoja-Barrios, S. (2020). Testing Statebuilding's 'Missing Link': Effects of Government Communications in Colombia. Journal of Development Studies, 56(3), 509526. https://doi.org/10.1080/00220388.2019.1585815

Pereira, J. M. B. A. (2012). O Facebook e a Comunicação Política: dos Usos e Gratificações à Análise de Redes, $1-178$.

Pina, A. R. B., Neri de Souza, F., \& Leão, M. C. (2013). Investigación educativa a partir de la informacion latente en internet. Revista Eletrônica de Educação, 7(2), 301-316.

Ribeiro, D., Costa, A. P., \& Remondes, J. (2020). Government Communication - The Dubai and United Arab Emirates Ministry of Happiness. In A. P. Costa, L. P. Reis, \& A. Moreira (Eds.), Computer Supported Qualitative Research: New Trends on Qualitative Research (WCQR 2019) - SPRINGER (pp. 226-238). Porto - Portugal: Springer International Publishing. https://doi.org/10.1007/978-3-030-31787-4_19

Ribeiro, D., Remondes, J., \& Costa, A. P. (2017). Comunicação do Ministério da Felicidade dos Emirados Árabes Unidos. Análise de dados qualitativos disponíveis na Internet. In António Pedro Costa, S. Tuzzo, \& C. Brandão (Eds.), Atas do 6o Congresso Ibero-Americano em Investigação Qualitativa (Volume 3 Investigação Qualitativa em Ciências Sociais) (pp. 686-691). Ludomedia. Retrieved from 
https://proceedings.ciaiq.org/index.php/ciaiq2017/article/view/1443

Ribeiro, D., Remondes, J., \& Costa, A. P. (2018). Análise de conteúdo na Comunicação Governamental - Estudo de Caso referente ao Ministério da Felicidade dos Emirados Árabes Unidos. CIAIQ2018, 3. Retrieved from https://proceedings.ciaiq.org/index.php/ciaiq2018/article/view/1743

Ribeiro, D., Remondes, J., \& Costa, A. P. (2019a). A Comunicação do Ministério da Felicidade do Dubai e Emirados Árabes Unidos no ano 2016. In Comunicação, Redes Sociais e a Produção Artistica (Vol. 1, p. 53 a 74). Atena Editora. https://doi.org/10.22533/at.ed.932191905

Ribeiro, D., Remondes, J., \& Costa, A. P. (2019b). Comunicação governamental: o exemplo do ministério da felicidade dos Emirados Árabes Unidos. Ámbitos. Revista Internacional de Comunicación, 44(44), 54-72. https://doi.org/10.12795/Ambitos.2019.i44.04

Ribeiro, D., Remondes, J., \& Costa, A. P. (2019c). Comunicação Governamental - O Ministério da Felicidade do Dubai e dos Emirados Árabes Unidos - O objetivo da criação do Ministério da Felicidade - análise de conteúdo. In CIAIQ19 - Congresso Ibero Americano de Investigação Qualitativa. Lisboa.

Ribeiro, D., Remondes, J., \& Costa, A. P. (2019d). Estudo de caso sobre a comunicação governamental relativa à criação do Ministério da Felicidade do Dubai e Emiados Árabes unidos. In Ciências Sociais Aplicadas: Entendendo as Necessidades da Sociedade 2 (Vol. 2, pp. 29-44). Brasil: Atena Editora. https://doi.org/10.22533/at.ed.2451925064

Sanderson, I. (2001). Performance Management, Evaluation and Learning in 'Modern' Local Government. Public Administration, 79(2), 297-313. https://doi.org/10.1111/1467-9299.00257

Sterling, J., Jost, J. T., \& Hardin, C. D. (2019). Liberal and Conservative Representations of the Good Society: A (Social) Structural Topic Modeling Approach. SAGE Open, 9(2), 215824401984621. https://doi.org/10.1177/2158244019846211

Viteritti Joseph P. (1997). The Environmental Context of Communication: Public Sector Organizations. In Handbook of Administrative Communication (pp. 79-100). 